\title{
Performance Improvement of the Grid 을 Connected PV Inverter System with ANN Controller
}

\author{
Sankara Phani Dileep Malyala, Sravani Sattimsetti, P.V.Prasuna
}

\begin{abstract}
The implementation of the PV system and its integration into the grid has been increased. In this process some power quality issues arise i.e. harmonics, voltage sags / surges, interruptions, flickers, transients, and this is due to non-linear loads, arc furnaces, frequent starting / stopping of electric motors, oscillating loads and interactions of different semiconductor devices. Within these interharmonics is one of the emerging power quality issues in grid-connected photovoltaic (PV) systems. Based on previous case studies and field measurements, evidence of interharmonic emission from maximum power point tracking is one of the leading causes of interharmonics in PV inverters. In this regard, MPPT parameters such as sampling rate and perturbation step size have a strong impact on the interharmonic characteristic of PV system, and to overcome these problems, a mitigating solution has been previously proposed, namely modifications of the MPPT algorithm so as to randomly select the sampling rate between the fast value and the slow value. By implementing this technique with an artificial neural network controller for the control of the inverter. With the proposed method, the voltage perturbations of the DC-link voltage as well as the harmonics of the grid currents are reduced and the performance of the MPPT and PV system has been increased. The performances of the proposed system has been validated on a MATLAB / SIMULINK software environment.

Keywords: Inverters, Interharmonic, maximum power point tracking (MPPT), photovoltaic (PV) systems, power quality, Artificial neural networks(ANN).
\end{abstract}

\section{INTRODUCTION}

The penetration of PV systems is increasing day by day, and at the same time challenging problems related to the grid, integration has emerged over the past 20 years. One of the emerging problems with the power quality of grid-connected Photovoltaic systems is the interharmonics. Interharmonics are defined as the non-integer times of the fundamental frequency [6]. Inverters are the potential source of interharmonic emissions for Photovoltaic systems observed both within the field measurements and the laboratory test environment [7] - [11]. The interharmonic emission limit is still under development and it can cause voltage flickering, fluctuations, and unintentional disconnection of PV systems.

Revised Manuscript Received on December 25, 2020.

* Correspondence Author

Malyala S Phani Dileep*, Department of EEE, Pragati Engineering College, Surampalem, India. Email: dileepphani@gmail.com

Sravani Sattimsetti, Department of EEE, Pragati Engineering College, Surampalem, India. Email: ssravanis217@gmail.com

P.V.Prasuna, Department of EEE, Pragati Engineering College, Surampalem, India. Email: vijayaprasuna175@gmail.com

(C) The Authors. Published by Blue Eyes Intelligence Engineering and Sciences Publication (BEIESP). This is an open access article under the CC BY-NC-ND license (http://creativecommons.org/licenses/by-nc-nd/4.0/)
Therefore, interharmonic emissions should be avoided in PV systems, and for which a reduction is also required [12]. The maximum power point tracking (MPPT) [8] - [11] is one of the most important causes of the interharmonics in PV systems, by which the disturbance of the voltage of the PV arrays during the tracking of the maximum power point (MPP) inevitably causes an intrinsic error caused are power fluctuations on the DC side, especially during steady-state operation. Based on the above analysis, a mitigating solution proposed for interharmonics in PV systems is nothing but randomly switching operation between a fast and slow sampling rate of the MPPT- Algorithm [12] in conjunction with the control of the artificial neural network [2] - [3] for the DC- link voltage control. This ANN control strategy is used to reduce the steady-state error and improve the ability to suppress harmonics and the rise time in the control. Therefore, the interharmonics within the output current are effectively reduced due to the distribution of the frequency spectrum and also peak overshoots in an output current that has been reduced due to the reduction in the DC-link voltage perturbation. This paper discussed the design of the proposed system and performance characteristics of the PI Controller Model in Section II, Modified Control Scheme in Section III. Simulation results \& Analysis and conclusions are elaborated in Section IV and V respectively.

\section{DESIGN OF PROPOSED SYSTEM}

\section{A. System Configuration}

The proposed system modelled on the Matlab / Simulink platform to improve the performance of the 1- $\Phi$ grid-connected photovoltaic inverter system as shown in Fig.1. The Random sampling technique [1][18] is implemented here to enhance the MPPT algorithm[14]tracking performance. The single-stage converter offers good efficiency, lower cost, and easier to implement. With this proposed model, the operation of the inverter control is can be done with a technique of DC-link voltage controller as well as the current controller. In this DC-link voltage control strategy, ANN[2]-[3] was implemented to reduce steady-state errors, harmonics rejection capability, and improvement in the rise time of the system. Whereas PR current control strategy to be used for zero steady-state error under the stationary reference frame using the PLL technique.

\section{Published By:}

Blue Eyes Intelligence Engineering and Sciences Publication

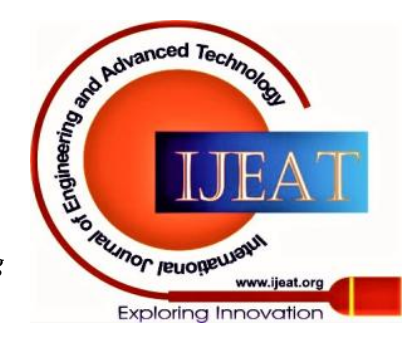


The LCL filter is employed between the grid and the inverter to attenuate the switching frequency harmonics produced through the inverter connected to the grid, it additionally has higher attenuation functionality of excessive order harmonics and higher dynamic characteristic.

In this proposed system power oscillation includes a sequence of low-order frequency components, which is reflected inside the frequency elements of the amplitude of the output current |ig |. When multiplying the frequency element of the amplitude of the output current |ig | with the phase angle $\sin (\theta g)$, the output current (ig ) will comprise a particular quantity of interharmonic frequencies due to the fact of the interaction of the time domain and frequency domain components in fig.1. To cope with interharmonics issue, a model was proposed [13] and analyzed the interharmonic attribute in PV structures however nevertheless required a greater specific investigation of the PV inverter[15] control primarily based on the DC control(Input) \& output(AC control) parameters of the system. With reference to the interharmonic characterization model[13] field observations[6]-[9] are well agreeable with simulation results. Based on the evaluation verified that the interharmonic attribute is strongly based on[1][13] the MPPT algorithm parameters like the Vstep (Perturbation Step size), and Fmppt (Sampling rate). As mentioned in earlier studies, the interharmonic emanation is often successfully captivated with the aid of the sampling rate of the MPPT algorithm[12]. However, this can inevitably abate the monitoring overall performance of the Maximum power point tracking algorithm due to the fact this efficiency of the MPPT reduces and accordingly the Photovoltaic power yield, in particular at some stage in various environmental stipulations (e.g., ambient temperature and insolation). Therefore, when selecting the Fmppt for the MPPT algorithm, there is a relationship between interharmonic emanation and MPPT efficiency.

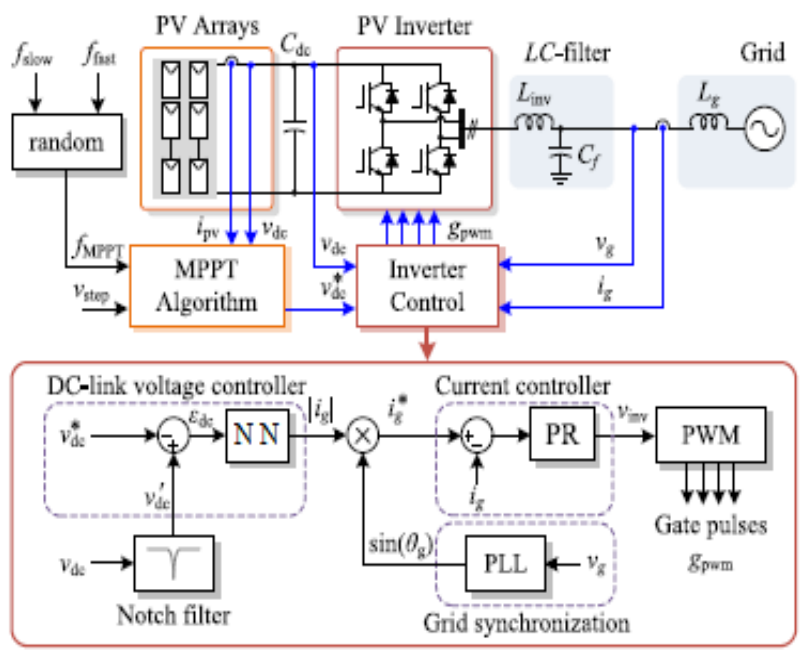

Fig. 1. Grid Connected PV Inverter System with ANN Controller

B. Performance Characteristics of PI Controller Model The MPPT algorithm plays a crucial role in the PV system to maintain the maximum power for the PV array and which enhance the power yield during the process. In this manuscript, the $\mathrm{P} \& \mathrm{O}$ (Perturb and Observe) Maximum power point tracking algorithm is engaged [14], where the Vstep(Perturbation step size) and the MPPT sampling rate (Fmppt) are the MPPT parameters. One imperative feature of the $\mathrm{P} \& \mathrm{O}$ MPPT algorithm is there is an intrinsic behavior in the steady-state operation [14] i.e. the Photovoltaic inverter operates under constant insolation condition. In which system operated in the Random sampling method[1] between 2.5 and $5 \mathrm{~Hz}$ to exhibit the performance of the Photovoltaic inverter system along with Conventional PI technique[1] as shown in fig.3 This scheme is similar to the random PWM(pulse width modulation) was discussed in the earlier research for the harmonic reduction in PWM switching [18]. The random selection of the sampling rate method is used in the MPPT algorithm for the proposed system . An easy way to execute this method is to randomly select the sampling rate of the MPPT algorithm during the process with either a high Ffast or a low Fslow value. This technique can apply to other MPPT algorithms because MPPT implementation is in similar principle. The significance of the randomly applying MPPT sampling rate is, there are perturbations in DC-link voltage, and due to which Peak overshoots in output current does not reduce due to which total harmonic distortions are above the specified limits[4] of the output current(ig) as shown in Fig.2.

With the PI-based DC- link voltage controller[1] along with the random sampling technique method, the THD of the harmonics is $6.03 \%$. In reality, the frequency spectrum is further distributed due to the arbitrarily applied perturbations of the output current. The voltage of the PV system varies within 3 operating points, same as like "top of the hill" of the PV curve. This is achieved if the sampling rate below the settling time of the PV power is correctly selected, as described in [16]. In particular, the MPPT sampling rate is proportional to the frequency of the oscillation.
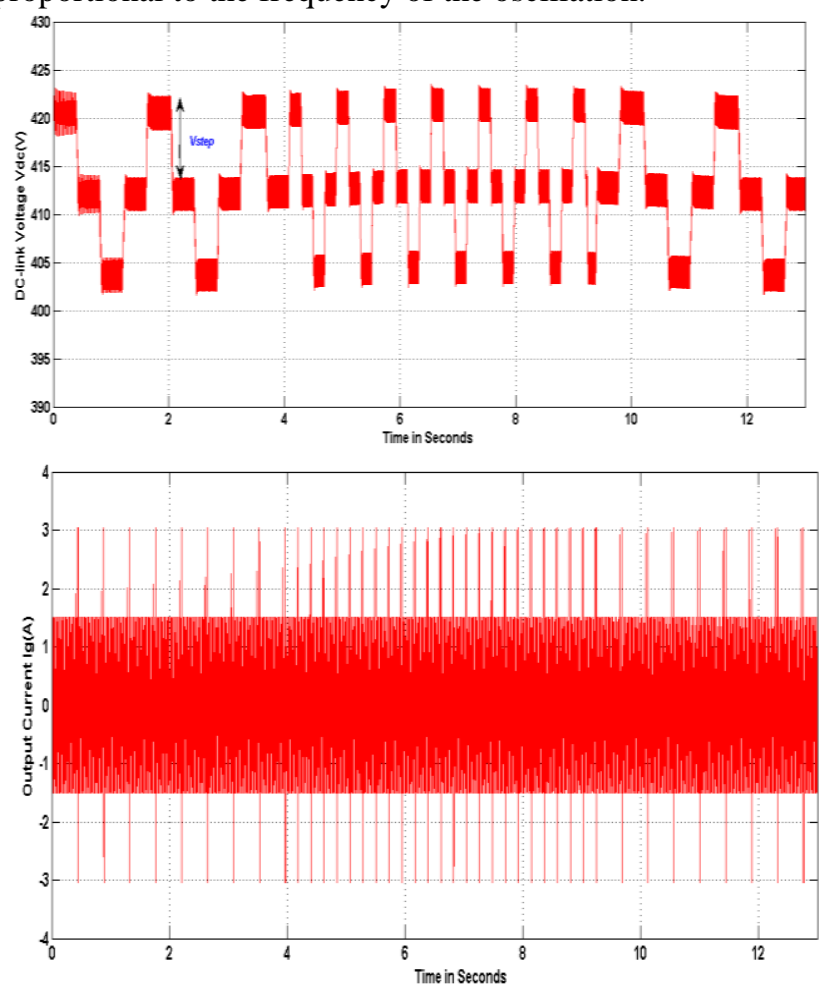

Published By:

Blue Eyes Intelligence Engineering and Sciences Publication (C) Convriaht: All riahts reserved. 

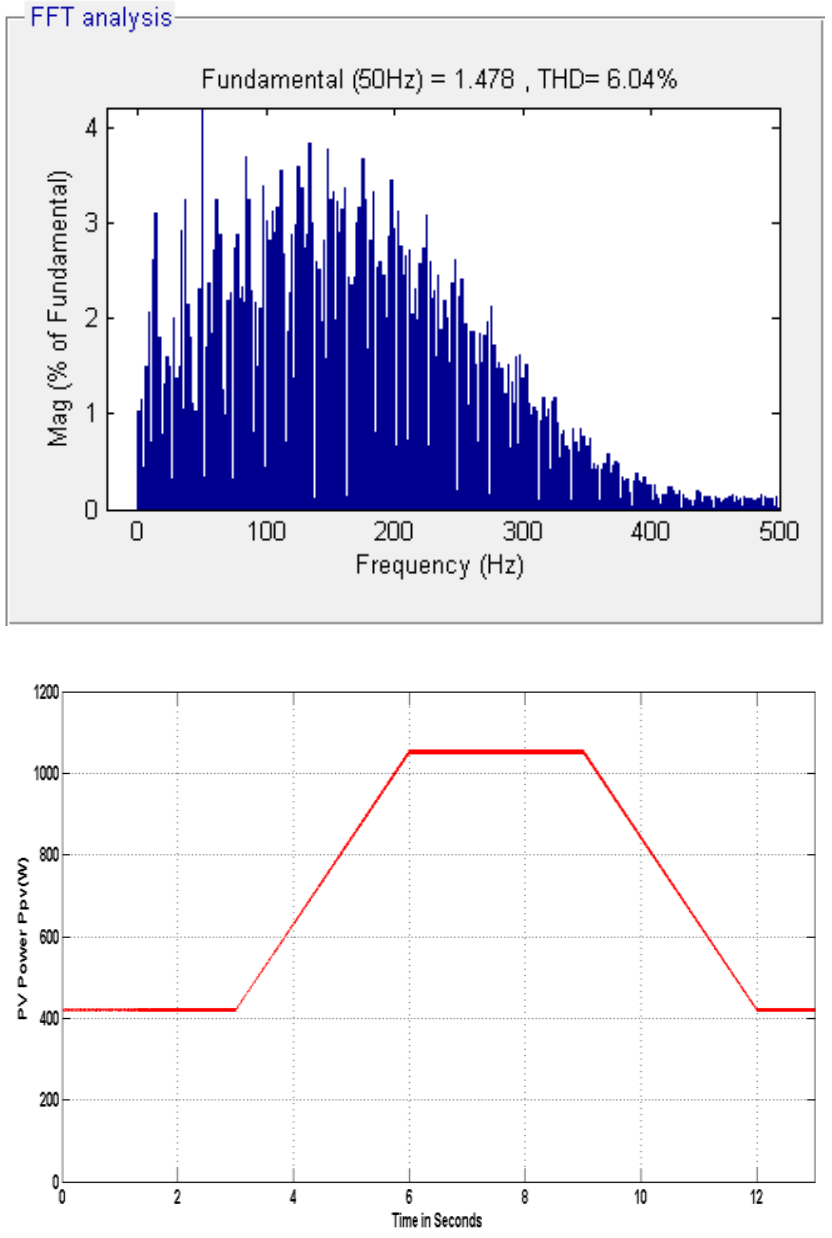

Fig.2. Simulation waveforms for the Random sampling MPPT technique with PI controller (i) DC-link Voltage Vdc(V) (ii) Grid Current ig(A) (iii) THD (\%) and (iv) PV Power Ppv (W)

\section{CONTROL SCHEME}

In this section, a modified control system technique for the DC- link voltage (Vdc) controller and its control algorithm is described.

\section{A. ANN for DC-link Voltage (Vdc) Controller}

For DC-link Voltage (Vdc) control, generally classic PI controller with MPPT reference voltage along with DC-link Capacitor feed-forward voltage is used and also The PI controller is considered based on the small-signal modelling of the system but this system exhibits two renowned drawbacks due to poor presentation of the integral actions i.e. incapability to track steady-state error and poor interruption elimination capability. An alternate resolution proposed in this document is an ANN as shown in fig 3. Compared to PI controllers with the an Artificial Neural Nnetwork Controllers[2]-[3] are provides a higher speed response in terms of the steady-state error and rise time. The reason behind performance improvement in neural network(NN) is due to generality property and also control surface of the NNC is smooth. It is a simple controller with 3 neurons, and due to this simplicity best implementation controller for an embedded system. Artificial Neural Network controller trained with the training data from a PI controller has enhanced response Characteristics compared to other controllers. So, during this work, the ANN controller is proposed, and therefore, the explanations of the ANN and also the respective control algorithm i.e. backpropagation algorithm[4]-[5] of the planned system is described below.

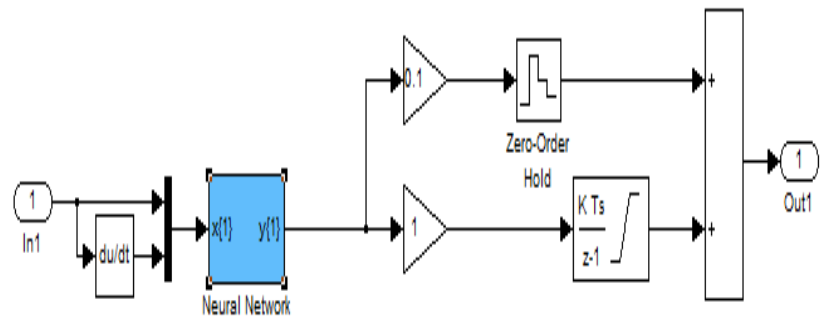

Fig. 3. Simulink model of ANN

\section{B. Backpropagation Algorithm for ANN Controller}

The breakthrough for the multilayer network was the development of a method for learning by the examples, called the backpropagation algorithm [4]-[5]and it is developed by Werbos and Rumelhart et al. This backpropagation algorithm has made it is possible to design multilayer networks for different applications, like adaptive control, stock market prediction, sonar and speech recognition. The FFNN(feed forward neural network) [2]-[5] is the most vital and generally used in ANN. The synthetic neural network considered within the proposed manuscript is qualified by BP (Backpropagation )[2]-[3] using the optimization technique supported LM (Levenberg-Marquardt). Levenberg-Marquardt is one of the foremost supervised learning algorithms for the FFNN. The BPNN provides the specified output supported the input, supported the training and weight parameters as shown in Fig.4. During this document, BPNN uses the input DC voltage and current from the output variable and generates a requirement cycle to regulate the converter/inverter switches to realize the specified performance. The BPNN is trained with two hidden levels. As a result, they need four layers in one is an input layer, the second is the hidden layer I, the third is the hidden layer II, and therefore, the last is an output layer. In these layers nodal operation of BPNN can be performed. The modelling of every layer is showned below and therefore, the input supplied to the BPNN is X and Y are is mentioned as the target output. The matrix form of the input and output is denoted as

$$
\begin{aligned}
& \mathrm{X}=\left[\begin{array}{l}
\mathrm{X} 1 \mathrm{X} 2 \mathrm{X} 3 \ldots . . . \mathrm{Xn}] \\
\mathrm{Y}
\end{array}\right. \\
& \mathrm{Y}=[\mathrm{Y} 1 \mathrm{Y} 2 \mathrm{Y3} \text {...... Yn ] }
\end{aligned}
$$

The samples of the input matrix are in use adequately to 820 by 2, and therefore, the output is 820 by 1 .In this layer process the input signals of the system and also Z-value calculates and it is passed to the next layer. This layer defines the maximum values \& minimum values of $\mathrm{X}$ and $\mathrm{Y}$ :

$$
\mathrm{Z}=(\mathrm{X}-\mathrm{Xmin}) \mathrm{K}+\mathrm{Ymin}
$$

here gain is $\mathrm{K}$, and it's coming from the below method

$$
\mathrm{K}=(\mathrm{Ymax}-\mathrm{Ymin}) /(\mathrm{Xmax}-\mathrm{Xmin})
$$

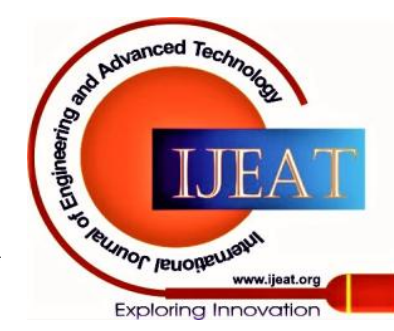




\section{Performance Improvement of the Grid Connected PV Inverter System with ANN Controller}

The input layer $\mathrm{Z}$ and is put to the input of the H1(Hidden layer I). The bias (B1) and Weight( W1) are calculated within the training epoch. The output of the $\mathrm{H}_{1}$ is represented below

$$
\mathrm{H}_{1}=(\mathrm{ZW} 1+\mathrm{B} 1) \log \text { sigmoid }
$$

This control approach is for 3 neurons, therefore the size of the load matrix is 820 by 3. moreover, the bias matrix is calculated as 2 by 3 . The output of the $\mathrm{H}_{1}$ (Hidden layer) is given as input to the H2(hidden layer II) and thus, the bias and weight of this layer are considered as B2 and W2, correspondingly. The output of the $\mathrm{H}_{2}$ is given as

$$
\mathrm{H}_{2}=(\mathrm{H} 1 \mathrm{~W} 2+\mathrm{B} 2) \log \text { sigmoid }
$$

The subsequent amplitude signal |ig | is obtained from the $\mathrm{H}_{2}$ layer of BPNN and multiplies the frequency component, i.e. output current amplitude |ig | from BPNN with the phase $\sin (\theta g)$ then generates Iref $*$ for current control and is compared with the output current (ig) then sends error signals to the proportional resonant controller(PR), from which the inverter PWM control Voltage value is generated, i.e. a requirement cycle factor is obtained. To get the specified output reverse mapping to be performed for the input of this layer $\mathrm{H}_{2}$. The output of the layer $\mathrm{Y}$ is used to the generate reference current signal for PR controller along with phase angle of the grid to control the PV inverter.

$$
\mathrm{Y}=\left(\mathrm{H}_{2}-\mathrm{Ymin}\right) \mathrm{K}+\mathrm{Xmin}
$$

Therefore, the above control strategy utilized in the below Simulink model Fig.4, a resultant duty cycle ratio for DC-DC or DC/AC converter is obtained based on the MPPT Algorithm. Although the BP algorithm is guaranteed to meet only a confined rather than a wide-ranging minimum of the error function, previous observations have displayed that in many problems it, in fact, converge to the global minimum. This algorithm is proven its effectiveness and usefulness in many applications. Aside from this other neural network algorithms like feedback network which is one can produce time-varying output from periodic, or chaotic motion, or possibly, eventually constant outputs. The feedback algorithm, [4]-[5] therefore, possesses richer types of behavior and therefore richer information processing capabilities. It is also worth to mention that the dynamics and stability properties of the continuous neural network which is an interesting topic for future research.

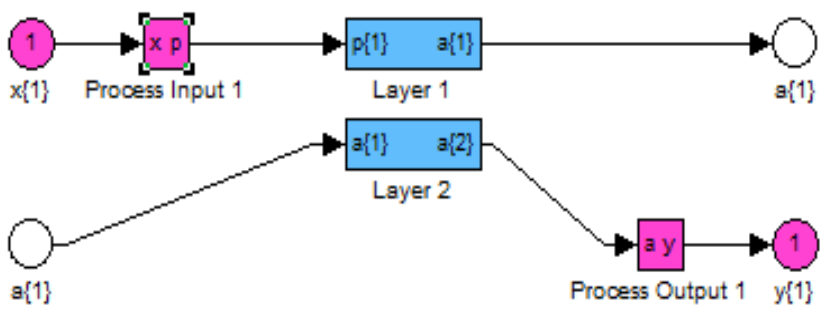

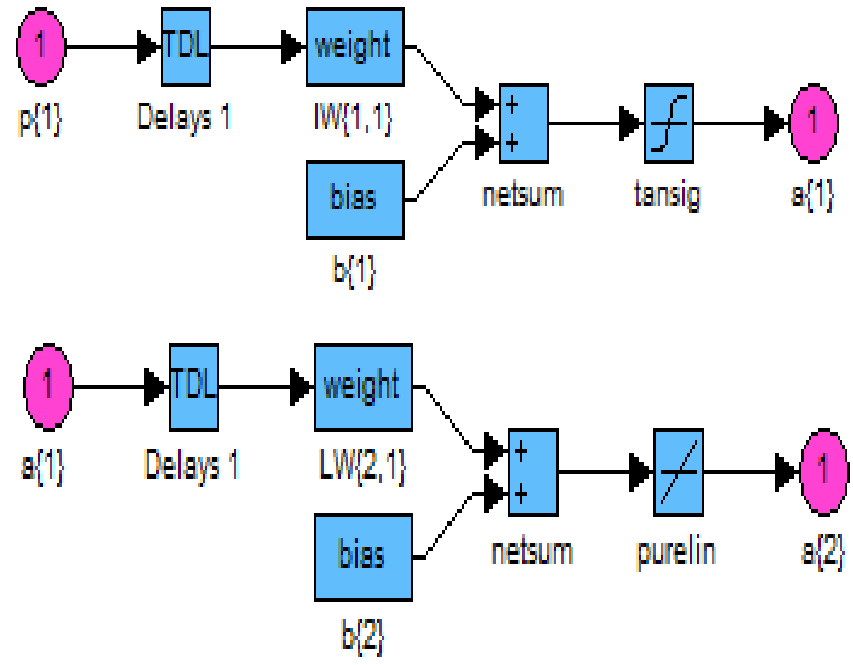

Fig. 4. Simulink model of the BPNN Algorithm

\section{Control Structure}

\section{DC-link voltage control}

Regarding the below Simulink model of Fig.5, an ANN controller receives the error signal(edc) from difference of the MPPT block and the Capacitor Voltage through notch filter to generate the magnitude of the current reference that should be used to control the inverter switches with help of the grid angle technique(PLL) to maintain the DC-link voltage at the Capacitor by tracking the reference value generated with the MPPT block. The immediate value of the output current reference is obtained simply by multiplying the magnitude of the current reference with phase angle of the grid.

\section{Grid angle detection}

The phase angle detection block plays a vital role in ensuring UPF(unity power factor) operation and in determining the reference output current as shown in Fig.5. The grid angle finding used in this application is based on the PLL technique.

\section{Current controller}

Regarding the Simulink model below in Fig.5, stationary reference frame PR Controllers in recent times become a feasible choice to rotational reference frame PI compensators in AC applications due to their capability to obtain a zero steady-state error without the need for a computationally concentrated reference frame transformations that make the operation of the grid-connected system more reliable and efficient.

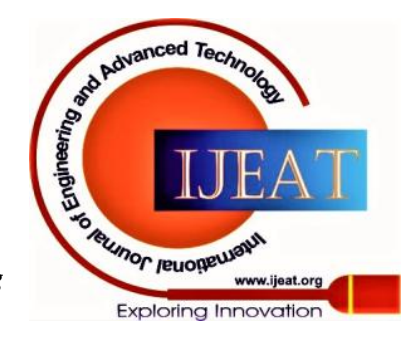




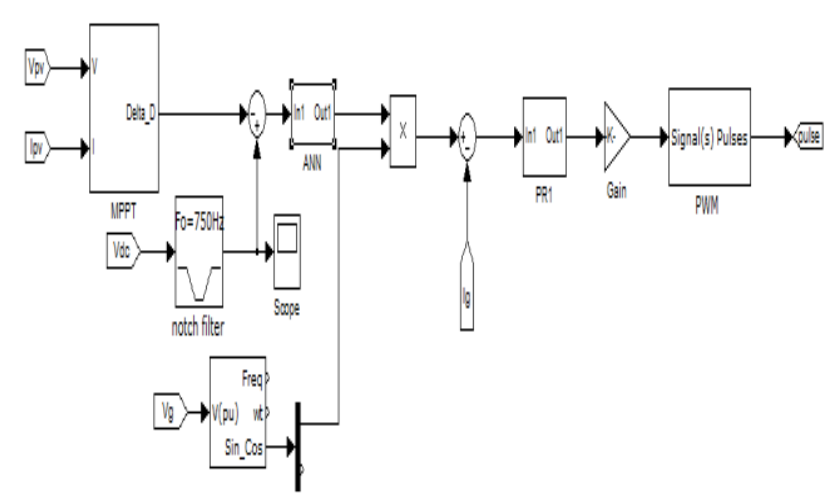

Fig. 5. Simulink model of Control Structure

\section{RESULT AND DISCUSSION}

The proposed method is Performance Improvement of the grid connected PV-Inverter System with ANN Controller and existing grid coupled PV-Inverter System with PI controller for DC-link Voltage control has been modelled in Matlab / Simulink environment and thus the simulation performance has been demonstrated here. The parameters and specifications of the PV system are shown in the Appendix and that simulation results are demonstrated here. During this simulation, the DC link voltage, output current, and THD analysis are the improvement parameters compared to the existing method. Below are the simulation analysis data for an equivalent as shown in Fig.6. Regarding the randomly applying MPPT sampling rate with ANN controller the perturbations in DC-link Voltage, Peak overshoot within the output current, and Total harmonic distortions within the output current are reduced compared to the PI controller as shown In Fig. 2. The corresponding MPPT sampling rate operation is also demonstrated in fig. 6. The frequency spectrum of the grid current has been analyzed for Total harmonics distortions (THD) and it is reduced from 6.04\% to $4.20 \%$ with the proposed method as shown in fig 6 . Due to the reduction of the interharmonics in the grid current with the proposed method, the overshoots of the grid current are reduced from $3 \mathrm{~A}$ to $1.8 \mathrm{~A}$, which is almost half the case when employing the existing method. The reduction of the current overshoots and noises in the frequency spectrum due to the reduction of the Perturbation step size (Vstep) from 9V to 6V in the Direct Current link voltage with the proposed method. With the ANN Controller perturbations in the DC-link voltage have been reduced and due to this ripple factor of the Direct Current link voltage has been reduced from 5\% to 3.1\%. Regarding the previous literature, the perturbation of Direct Current link voltage will certainly end in an immediate change in the grid current amplitude |ig| due to cascade configuration, and these oscillations are propagated to the output current(ig) through the amplitude modulation between the grid amplitude current |ig| and phase angle of the output voltage $\sin (\theta g)$ as shown in fig.1. Therefore, Direct Current link voltage control with the ANN controller improves the system performance in terms of Direct Current (DC) link voltage perturbations, Peak overshoots, and the Total harmonic distortions in the output current. Thus, the performance of the MPPT has been improved compared to the PI controller, and due to which PV-inverter system performance also got improved.

\section{A. Simulation Waveforms}
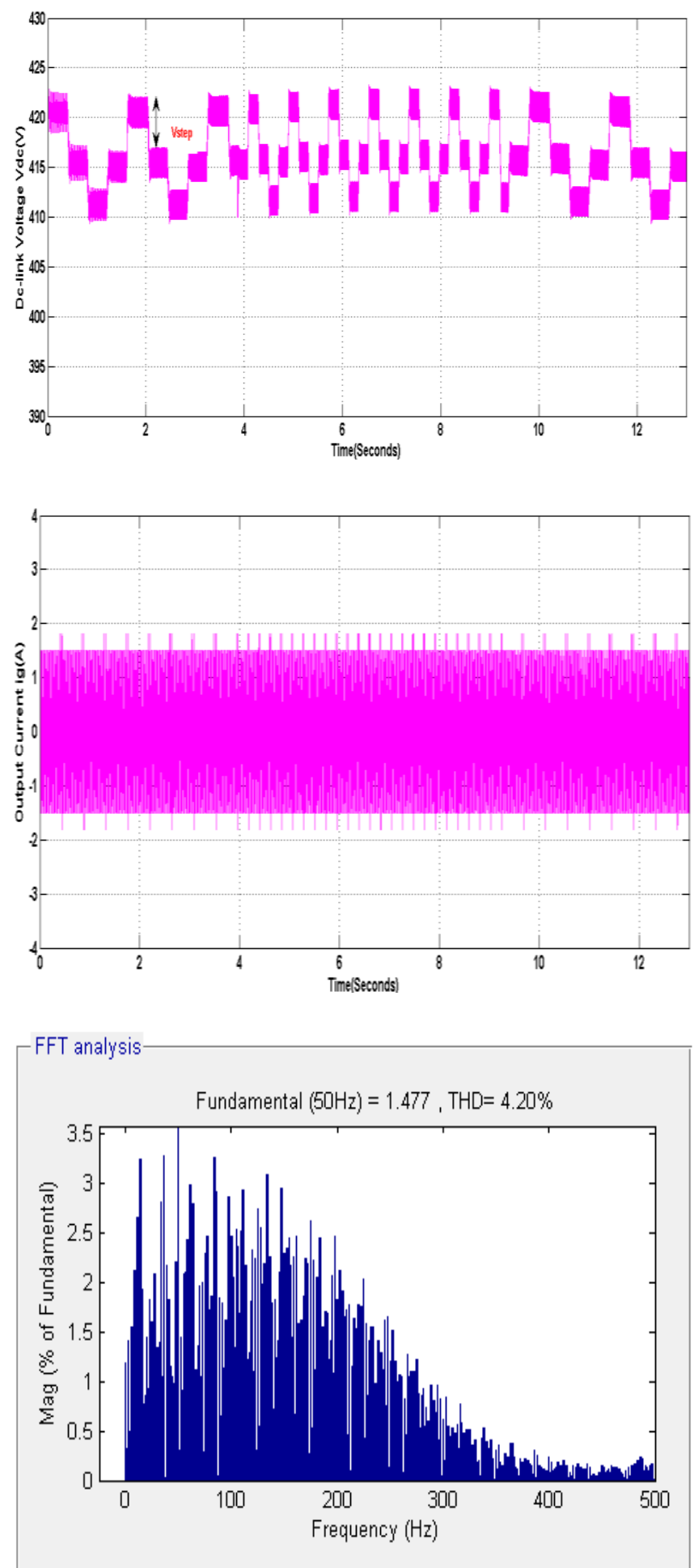

Published By: 
Performance Improvement of the Grid Connected PV Inverter System with ANN Controller

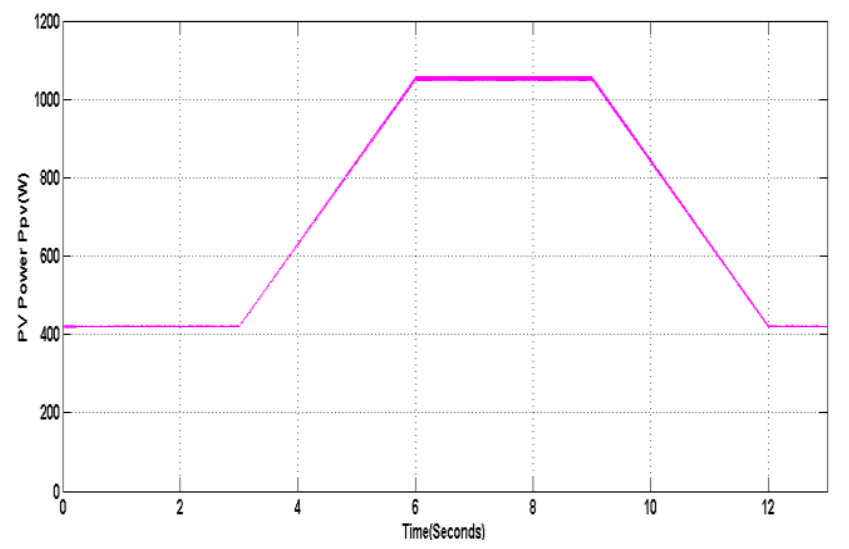

current link voltage ripples factor can be notably reduced. Moreover, the performance of the PV-Inverter system has been improved due to the reduction of interharmonics in the system. The performance of the proposed method have been validated with the Matlab/Simulink software environment. It can be developed furthermore with other control techniques, i.e., Feedback Linearization control, Fuzzy-Neural Network, and High Order Adaptive SMC will be designed and compared with existing ones and also dynamics and stability properties for the continuous neural network which is an exciting topic for future research.

\section{APPENDIX}

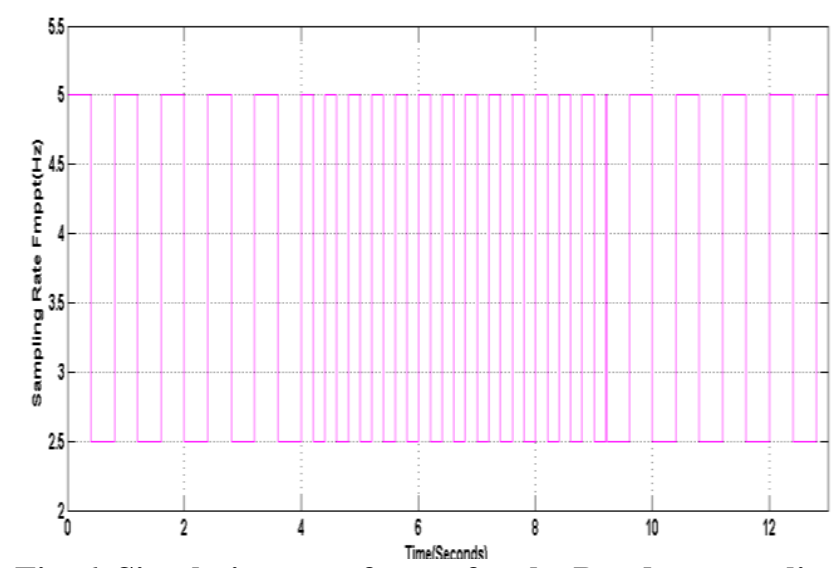

Fig .6. Simulation waveforms for the Random sampling MPPT technique with ANN controller (i) Direct Current link Voltage Vdc(V) (ii) Grid Current ig(A) (iii) THD (\%) and (iv) PV Power Ppv (W) (v) MPPT Sampling rate $\operatorname{Fmppt}(\mathrm{Hz})$

\section{B. Comparison between PI and ANN Controllers}

TABLE-I: Comparison between PI and ANN Controller

\begin{tabular}{|c|c|c|c|c|}
\hline \multirow{2}{*}{ S.NO } & \multirow{2}{*}{ Parameters } & \multicolumn{2}{|c|}{ Controller } & \multirow{2}{*}{$\begin{array}{l}\text { Improvements } \\
\text { Reductions }\end{array}$} \\
\hline & & PI & ANN & \\
\hline 1 & Peak to Peak DC-link Voltage( Vdc) & $402 \mathrm{~V}-423 \mathrm{~V}$ & $410 \mathrm{~V}-423 \mathrm{~V}$ & $8 \mathrm{~V}$ \\
\hline 2 & DC-link Voltage Ripple factor(\%) & $5 \%$ & $3.10 \%$ & $1.90 \%$ \\
\hline 3 & Perturbation Step Size(Vstep) & $9 \mathrm{~V}$ & $6 \mathrm{~V}$ & $3 \mathrm{~V}$ \\
\hline 4 & Peak Overshoots in output current (ig) & $3 \mathrm{~A}$ & $1.8 \mathrm{~A}$ & $1.2 \mathrm{~A}$ \\
\hline 5 & Total Harmonics Distortions(\%) & $6.04 \%$ & $4.20 \%$ & $2.20 \%$ \\
\hline
\end{tabular}

Parameters Of The 300w Single Phase Grid-Connected Pv Model

\begin{tabular}{|l|l|l|}
\hline \multicolumn{1}{|c|}{ Parameters } & \multicolumn{1}{c|}{ Signs } & \multicolumn{1}{c|}{ Ratings } \\
\hline Output Voltage (RMS) & $\mathrm{Vg}$ & $230 \mathrm{~V}$ \\
\hline Frequency(Grid) & $\mathrm{Fg}$ & $50 \mathrm{~Hz}$ \\
\hline Sampling frequency of the Controller & $\mathrm{Fs}$ & $20 \mathrm{KHz}$ \\
\hline Grid- side inductance & $\mathrm{Lg}$ & $2 \mathrm{mH}$ \\
\hline Voltage Capacitance for DC-link ( Vdc) & Cdc & $2200 \mathrm{uF}$ \\
\hline LC Filter & Linv,Cf & $4.8 \mathrm{mH}, 4.3 \mathrm{uF}$ \\
\hline Switching Frequency of the Inverter & Finv & $8 \mathrm{KHz}$ \\
\hline
\end{tabular}

\section{REFERENCES}

1. Ariya Sangwongwanich, and Frede Blaabjerg, "Mitigation of Interharmonics in PV Systems With Maximum Power Point Tracking Modification," IEEE TRANSACTIONS ON POWER ELECTRONICS, VOL. 34, NO. 9, SEPTEMBER 2019.

2. Aleksander, I., Morton, H. 1995. An Introduction to Neural Computing ( $2^{\text {nd }}$ ed). Chapman and Hall.

3. McCulloch, W.S., Pitts, W. 1943. A Logical Calculus of the Ideas Immanent in Nervous Activity. Bulletin of Mathematical Biophysics, Vol 5, pp 115-133. Reprinted in Anderson \& Rosenfeld, 1988, pp 18-28.B. Smith, "An approach to graphs of linear forms (Unpublished work style)," unpublished.

4. Fausett, L. 1994. Fundamentals of Neural Networks : Architectures, Algorithms and Applications. Prentice-Hall, ISBN 0-13-103805-2.

5. W.Roberts and D.Harline,"Separation of multi-unit impulse trains by a multi-channel linear filter algorithm," Brain Res., Vol.94, pp. 141-149,1975.

6. M. Aiello, A. Cataliotti, S. Favuzza, and G. Graditi, "Theoretical and experimental comparison of total harmonic distortion factors for the evaluation of harmonic and interharmonic pollution of grid-connected photovoltaic systems," IEEE Trans. Power Del., vol. 21, no. 3, pp. 1390-1397, Jul. 2006.

7. T. Messo, J. Jokipii, A. Aapro, and T. Suntio, "Time and frequencydomain evidence on power quality issues caused by grid-connected threephase photovoltaic inverters," in Proc. Eur. Conf. Power Electron. Appl., Aug. 2014, pp. 1-9.

8. R. Langella, A. Testa, S. Z. Djokic, J. Meyer, and M. Klatt, "On the interharmonic emission of PV inverters under different operating conditions," in Proc. Int. Conf. Harmonics Quality Power, Oct. 2016, pp. 733-738.

9. R. Langella, A. Testa, J. Meyer, F. Mller, R. Stiegler, and S. Z.Djokic, "Experimental-based evaluation of PV inverter harmonic and interharmonic distortion due to different operating conditions," IEEE Trans. Instrum. Meas., vol. 65, no. 10, pp. 2221-2233, Oct. 2016.

\section{CONCLUSION}

With the Random sampling MPPT technique with PI controller implementation, DC-link voltage Perturbations, Peak overshoots in the output current, and harmonic distortions are still present in the system. To avoid these issues, a new mitigating solution has been proposed in this paper. The proposed method modifies with the Artificial Neural Network controller in place of a PI controller for DC-link voltage control. By doing, so, Perturbations in DC-link Voltage, Peak overshoots in output/grid current, the perturbation step size, total harmonic distortions, and Direct

Blue Eyes Intelligence Engineering and Sciences Publication

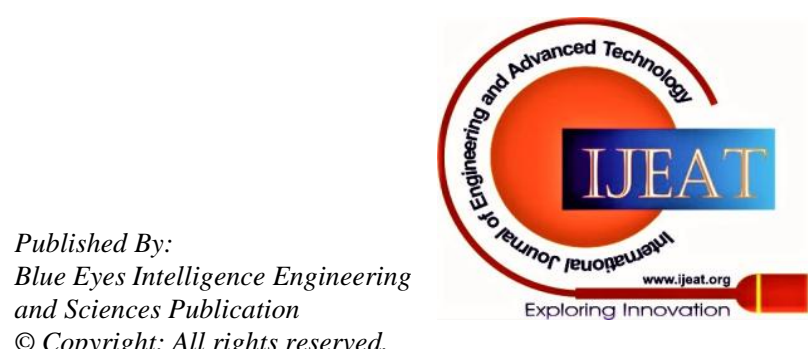
power plant induced power quality problems - experimental evidence," in Proc. Eur. Conf. Power Electron. Appl., Sep. 2016, pp. 1-10.

11. V. Ravindran, S. K. Rnnberg, T. Busatto, and M. H. J. Bollen, "Inspection of interharmonic emissions from a grid-tied PV inverter in north Sweden," in Proc. Int. Conf. Harmonics Quality Power, pp. 1-6, May 2018. 
12. Testa et al., "Interharmonics: Theory and modeling," IEEE Trans.Power Del., vol. 22, no. 4, pp. 2335-2348, Oct. 2007.

13. Sangwongwanich,Y.Yang, D. Sera,H. Soltani, and F.Blaabjerg, "Analysis and modeling of interharmonics from grid-connected photovoltaic systems," IEEE Trans. Power Electron., vol. 33, no. 10, pp. 8353-8364,Oct. 2018.

14. N. Femia, G. Petrone, G. Spagnuolo, and M. Vitelli, "Optimization of perturb and observe maximum power point tracking method," IEEE Trans.Power Electron., vol. 20, no. 4, pp. 963-973, Jul. 2005.

15. B. Kjaer, J. K. Pedersen, and F. Blaabjerg, "A review of singlephase grid-connected inverters for photovoltaic modules," IEEE Trans.Ind. Appl., vol. 41, no. 5, pp. 1292-1306, Sep. 2005.

16. J. Kivim“aki, S. Kolesnik, M. Sitbon, T. Suntio, and A. Kuperman, "Design guidelines for multiloop perturbative maximum power point tracking algorithms," IEEE Trans. Power Electron., vol. 33, no. 2, pp. 1284-1293,Feb. 2018

17. H. Schmidt, B. Burger, U. Bussemas, and S. Elies, "How fast does an MPP tracker really need to be?" in Proc. Eur. Photovoltaic Solar Energy Conf., Sep. 2009, pp. 3273-3276.

18. F. Blaabjerg, J. K. Pedersen, and P. Thoegersen, "Improved modulation techniques for PWM-VSI drives," IEEE Trans. Ind. Electron., vol. 44 no. 1, pp. 87-95, Feb. 1997.

\section{AUTHORS PROFILE}

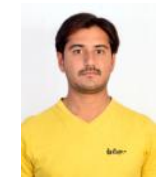

Mr. Malyala S Phani Dileep, Graduated from Rajalakshmi Engineering College, Chennai. He is presently pursuing M.Tech in the Department of Electrical and Electronics Engineering, Pragati Engineering College, Surampalem, Peddapuram. His research areas include Power Electronics Converters, Renewable energy systems, and storage systems.

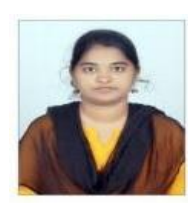

Ms.S.Sravani, Post Graduated from Kits, Ramachandrapuram. She is presently working as Assistant Professor in the Department of Electrical and Electronics Engineering, Pragati Engineering College, Surampalem, Peddapuram. She had published 2 research papers in National journals. Her research area is Power Systems. She has an IAENG membership.

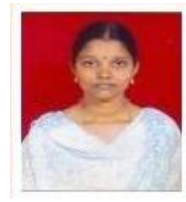

Mrs.P.V.Prasuna, Post Graduated from BVC Engineering College, Odalarevu. She is presently working as Associate Professor in the Department of Electrical and Electronics Engineering, Pragati Engineering College, Surampalem, Peddapuram. She had published 1 research paper in National journals, Six research papers in International

Journals and 1 research paper in national Conference. Her research areas include Power Electronics, Control Systems, Electrical Machines and Power Systems. She has an IAENG member ship and in her guidance student won an cash prize in Smart India Hackathon-2017.

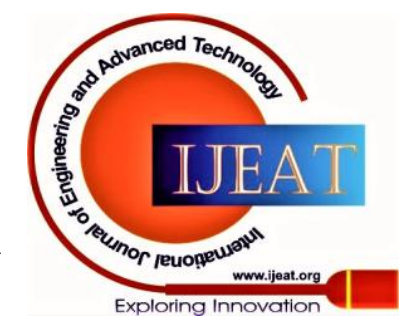

